\title{
Promesas biotecnológicas. Determinismo genético, cáncer y maternidad por sustitución: un análisis crítico
}

\author{
Biotechnology Promises. Genetic Determinism, Cancer and \\ subrogated motherhood: A Critical Analysis
}

EULALIA PÉREZ SEDEÑO*

\begin{abstract}
Resumen: La biotecnología, sobre todo a partir del desciframiento del genoma humano, ha ofrecido muchas promesas, en su mayoría aún sin cumplir. Mediante el análisis feminista de algunas de estas promesas y el del caso de la maternidad por sustitución, veremos cómo los objetivos, fines e imaginarios de estas biotecnologías afectan de manera desigual a las mujeres y pueden ayudar a perpetuar las desigualdades existentes y el papel subordinado de las mujeres en nuestras sociedades. Análisis de este tipo pueden alertar al respecto y ayudar a minimizar los daños.

Palabras clave: Biotecnología; determinismo genético; cáncer de mama; maternidad por sustitución; género y ciencia.
\end{abstract}

\begin{abstract}
Biotechnology, especially since the decipherment of the human genome, has offered many promises, most of which are still unfulfilled. Through the feminist analysis of some of these promises and the case of subrogated motherhood, we will see how the goals, ends and imaginary of these biotechnologies unequally affect women and can help to perpetuate existing inequalities and the subordinate role of Women in our societies. Analysis of this type can alert about, and help to minimize, damages.

Keywords: Biotechnology; genetic determinism; breast cancer; subrogated motherhood; gender and science.
\end{abstract}

\section{Introducción}

Hace ya varias décadas que el feminismo centró su atención en la ciencia y la tecnología. De hecho, fue Signs: Journal of Women in Culture and Society, la primera revista en publicar un número especial dedicado a los estudios feministas de la ciencia en otoño de 1978, tan sólo tres años después de que comenzara a publicarse esta revista, dedicada a estudios generales sobre las mujeres en la cultura y la sociedad. Titulado "Women, Science and Society", los trabajos que aparecían en este volumen se centraban en áreas que marcarían los estudios posteriores: la situación de las mujeres en las profesiones científicas, con consideraciones sobre las políticas públicas al respecto, la historia de las mujeres en la ciencia y críticas 
a los sesgos sexistas de determinadas teorías científicas. Como he señalado en otro lugar (Pérez Sedeño, 2016) las editoras de este volumen anticiparon los debates y las críticas que surgirían del acercamiento crítico feminista a la ciencia ${ }^{1}$.

Como institución social que es, la ciencia (y la tecnología) reproduce y replica las estructuras de poder que hay en ella. Dicho de otro modo, la ciencia y la sociedad se co-producen y se co-constituyen mutuamente. Lejos de esa neutralidad valorativa afirmada por cierta filosofía de la ciencia, la política la impregna y, por tanto, el sexo, el género, la raza, la clase social y otras variables, están en ella, como estructuras de poder que son.

La irrupción de la biotecnología en el panorama de la investigación y la innovación, ha puesto de relieve nuevos problemas. Y desde el feminismo debemos plantearnos las dimensiones de género de la biotecnología, en especial cómo y en qué medida las ideologías e ideas de género conforman las innovaciones en biotecnología, qué cuestiones o problemas se plantean (y cuáles no) y cómo la biotecnología afecta o conforma las vidas de las mujeres, para bien o para mal: es decir, si mejora la vida de las mujeres, si las empodera o si, por el contrario, las mantiene en los márgenes y las sigue manteniendo como grupo vulnerable.

\section{Las promesas del Proyecto Genoma Humano}

El despegue de la biotecnología se produce en los años setenta, pero recibió un impulso enorme tras la reunión de Asilomar ${ }^{2}$ del año 2000. En esta reunión se llegó a la conclusión de que las circunstancias de ese momento eran diferentes a las de los años setenta, por el mayor interés económico y social existente, por lo que no debían ser sólo los científicos quienes se preocuparan y analizaran los riesgos -de todo tipo-derivados de su trabajo y que una mayor implicación de quienes hacen ciencia en los debates públicos habría enriquecido todo el proceso social (Muñoz Ruiz, 2001).

La importancia económica y social se hizo patente cuando, en junio de 2000, el consorcio de laboratorios públicos International Human Genome Sequencing Consortium y su competidora privada, Celera Genomics, anunciaron que habían completado el borrador del genoma humano. El proyecto genoma humano (HGP por sus siglas en inglés) había comenzado en Estados Unidos en 1990, con un presupuesto de tres mil billones de dólares (aunque desde 1987 había centros de investigación en genoma humano). Pronto pasó a ser un proyecto de cooperación internacional del G7, el grupo de los siete países más ricos del mundo: Estados Unidos, Alemania, Japón, Francia, Italia, Gran Bretaña y Canadá.

Para justificar las enormes cantidades de dinero invertido en estos descubrimientos, las compañías biotecnológicas, los financiadores y los participantes del proyecto prometieron que el proyecto proporcionaría avances científicos y médicos importantes. Francis Collins, que sucedió en 1993 a James Watson como director de la rama estadounidense del HGP, afirmaba que en 2010 habría pruebas preventivas para por lo menos una docena de enfermedades hereditarias, que se eliminarían enfermedades de este tipo, como la hemofilia, y

1 En español, el primer número de una revista dedicado exclusivamente a género y ciencia fue el editado por mí misma en la Revista Arbor, 1992.

2 Estas reuniones se celebraron en Asilomar, California, desde el año 1973 y (al igual que las directrices emanadas de otros organismos) pueden entenderse como una propuesta de gestión y regulación de la propia comunidad tecnocientífica (Larrión, 2011). 
que en el 2020 habría tratamientos exitosos que repararían los genes mutados. La idea se basaba en la promesa de que el conocimiento del genoma proporcionaría nuevas perspectivas importantes en la etiología de la enfermedad, lo que posibilitaría una serie de avances tales como pruebas genéticas, fabricación de fármacos para perfiles genéticos específicos y el uso de terapia génica para corregir o compensar las mutaciones en el ADN (Collins et al., 2003). Así, se aceptaba el supuesto de que todas las características de los individuos, y también las enfermedades, se pueden explicar en términos biológicos, en este caso por la genética. Y aún más, se suponía una relación lineal entre ADN y rasgos fenotípicos. Este determinismo biológico reduccionista se manifiesta en el campo médico cuando se concibe la salud como una propiedad intrínseca y exclusiva del organismo, en vez de una relación de equilibrio entre los cuerpos humanos y su entorno. La diversidad genética natural presenta problemas de incompatibilidad o malos ajustes al entorno que el reduccionismo genético trata exclusivamente como síntomas de enfermedad orgánica, de 'defectos', en vez de variaciones socialmente inadecuadas del funcionamiento del cuerpo.

En cierto sentido, las promesas de lo que ofrecería la secuenciación masiva están bien fundamentadas. Evelyn Fox Keller (2002), aunque bastante reacia con respecto a los méritos del HGP, argumentaba que lo más valioso de este programa de investigación es que dejaría al descubierto las incoherencias del determinismo biológico y la veneración casi religiosa que se tiene por los genes. Parece que tenía razón, pues los científicos revelaron en 2001 que su análisis del mapa genético humano, completado ocho meses antes, había expuesto notables defectos en el conocimiento anterior. Al examinar el genoma humano, en vez de los previstos 100.000 o 150.000 genes, el consorcio público estimó que el genoma humano tenía unos 31.000 genes y que sus secuencias codificadoras de proteínas equivalían tan sólo al 1,5\% del ADN total. Ahora sabemos que los 20.500 genes de los humanos (International Human Genome Sequencing Consortium, 2004) son apenas 5.000 más que los de una mosca de la fruta (15.016) y unos 5.000 menos que los que tiene la planta herbácea Arabidopsis Thaliana (25.498), la primera planta de la que se secuenció el genoma. No parecía haber relación consistente entre la complejidad biológica de los diferentes organismos y el volumen de ADN y de cromosomas en sus genomas (las células de las ranas, por ejemplo tienen mucho más ADN que las de los seres humanos). Quedaba en entredicho la mencionada relación lineal entre ADN y rasgos fenotípicos.

Sin embargo, la genética médica sigue adoptando un reduccionismo genético que se manifiesta en la obsesión por enfermedades "causadas" por defectos en un solo gen. Aunque no dudamos de que a los científicos les animen fines humanitarios o intelectuales, centrarse en las enfermedades de un solo gen es bueno para los intereses comerciales, pues se pueden crear mercados para intervenciones médicas nuevas y más provechosas. Esas intervenciones pueden ser tan intrusivas para el cuerpo humano que provoquen riesgos considerables, debido a la complejidad del funcionamiento del organismo. Y, sin embargo, popularmente se nos presenta una etiología de la enfermedad a través de una explicación lineal de los desórdenes de un solo gen, realzando la posibilidad de que se pueda corregir genéticamente.

Lo cierto es que los desórdenes producidos por un solo gen son una fracción muy pequeña de todas las enfermedades, aproximadamente el dos por ciento. Algunas de estas enfermedades, además, afectan a un número muy pequeño de personas. Hay tres tipos de enfermedades monogénicas: las autosómicas recesivas, las autosómicas dominantes (ambos 
tipos transmitidos por los cromosmas no sexuales) y las ligadas al cromosoma X. Unas 200 condiciones hereditarias están registradas como desórdenes autosomáticos dominantes ${ }^{3}$. Por ejemplo, la hipercolesterolemia (1 por cada 500 nacidos vivos) la enfermedad de riñón poliquístico (1:1.000), la retinitis pigmentosa (1:4.000), la esclerosis tuberosa (1:5.800), la distrofia miotónica (1:8.000) o la enfermedad de Huntingdon (1:10.000). Los desórdenes recesivos autosómicos son más numerosos (se han identificado unos 900), pero se presentan con menos frecuencia, con una media de alrededor de 2,5 por cada 1.000 nacidos vivos. La proporción de los desórdenes vinculados al cromosoma $\mathrm{X}$ es mucho menor y su incidencia menos común que las anteriores debido a que el cromosoma $X$ constituye sólo el cinco por ciento del genoma total. Éstos incluyen defectos de la visión del color (8:100), o la hemofilia A (1:5.000 en varones).

En numerosos casos, esas enfermedades resultan ser mucho más complicadas y variables que lo que implican "desórdenes monogénicos", e incluso algunos científicos médicos rechazan dicha noción, pues hay una gran variedad de mutaciones genéticas asociadas a fenotipos idénticos y una amplia variedad de fenotipos asociados a mutaciones genéticas idénticas. Los genetistas reconocen que las enfermedades denominadas "multifactoriales", como el cáncer, son mucho más numerosas y son el resultado de la interacción de numerosos factores internos y externos; pero el peligro del reduccionismo genético continúa. El problema es que, en la imaginación popular (y médica) la enfermedad desencadenada por patógenos externos se reduce a "defectos heredados" susceptibles de intervención correctora o preventiva. Igual que sucede cuando se centran en los desórdenes de un solo gen, también aquí es preocupante que deje de prestarse atención a las causas sociales colectivas de la enfermedad o la discapacidad.

Muchas de estas enfermedades son dolorosas y angustiosas, pueden producir incapacidades y deterioros serios, que requieren cuidados médicos frecuentes y que a menudo acortan terriblemente la vida. Sin embargo, la explicación estándar médica de estas enfermedades como enfermedades de un solo gen y que, debido a la simplicidad de su etiología, son objetivo primordial de intervenciones genéticas, tiene sus errores. Un buen ejemplo es la fibrosis quística ${ }^{4}$ la más letal y común de las enfermedades recesivas autosomáticas entre los caucásicos. La fibrosis quística está causada por la mutación de un gen en el cromosoma siete. Dos tercios de los pacientes con fibrosis quística muestran una mutación que produce que no se exprese un determinado aminoácido, la felilalanina. Pero, la frecuencia de esta mutación entre las personas con fibrosis quística varía considerablemente según diferentes grupos étnicos y poblaciones. Además, se han descubierto otras mutaciones. La imagen se complica más si vemos que en 1995 se habían identificado unas 100 alteraciones secuenciales en el gen CFTR y se habían clasificado como variaciones "benignas" o polimorfismos. Este es un ejemplo que muestra que una condición heredada se resiste a la reducción genética simple, pero no es la única. Los síntomas de la hemofilia B, por ejemplo se han asociado

3 En este caso, sólo se necesita una copia mutada del gen para que la persona esté afectada. Basta con que uno de los dos progenitores padezca la enfermedad y la probabilidad de transmitir el gen mutado a su descendencia será del $50 \%$.

4 Afecta principalmente a los pulmones, aunque también puede afectar al páncreas, hígado e intestino, provocando la acumulación de moco espeso y pegajoso en estas zonas. Común en niños y adultos jóvenes puede ser mortal debido a infecciones pulmonares. 
con 200 variaciones nucleótidas diferentes, y lo mismo sucede con la talasemia en la que diferentes variaciones del ADN causan la enfermedad. Los expertos en esta enfermedad reconocen que no es un solo desorden de hecho, sino un grupo de síntomas clínicos, según el tipo y número de genes afectados así como según el grado de alteración y que puede ir de una anemia suave, a una potencialmente fatal. Resumiendo, hay muchos ejemplos de enfermedades supuestamente provocadas por un solo gen que tienen síntomas variados, mutaciones distintas, etc.

Por todo lo que hemos visto, está claro por qué ahora muchos genetistas médicos mantienen que no hay enfermedades de un solo gen y que los genes no pueden ejercer su influencia solos. Y eso resulta aún más claro cuando pasamos de las enfermedades congénitas y consideramos la inmensa mayoría de condiciones médicas que no se ajustan al modelo determinista de "un-gen-un-fenotipo". Aunque han fallado la mayoría de los intentos por efectuar asociaciones firmes entre genes y condiciones como el asma, la obesidad, la hipertensión, la esquizofrenia, y por supuesto con rasgos más borrosos como la agresión, la adición, la preferencia sexual, la inteligencia y la creatividad, se han correlacionado con éxito algunas condiciones médicas con genotipos que se considera que aumentan la "susceptibilidad"5 de las personas a padecerlas. Nos referimos a ciertas enfermedades genéticas como el cáncer de mama, el cáncer de colon, algunas formas de diabetes tipo dos y la enfermedad de Alzheimer. Pero en estos casos las mutaciones identificadas dan cuenta de menos del $3 \%$ de todos los casos y se considera que estos casos son causados por la acción combinada con las interacciones de más de un alelo, o "multifactoriales" (causadas por la interacción de genotipos heredados con factores medioambientales y fisiológicos).

Cuando se considera que las enfermedades con orígenes externos son genéticas, se medicaliza, de forma efectiva, lo que a menudo son problemas esencialmente sociales, económicos y medioambientales. El caso del cáncer de mama y lo sucedido en EEUU es interesante. En 1990, se fundó en San Francisco la Breast Cancer Action (BCA). El grupo fundador, que en su mayoría tenía cáncer de mama por metástasis, pretendía prevenir el aumento y reducir el número de casos. En el año 2000 el BCA se unió a otros grupos para lanzar la campaña "parar el cáncer donde comienza". Su objetivo fundamental era llamar la atención sobre las causas medioambientales de dicha enfermedad, como la exposición a pesticidas. Su lema no es sólo "lo personal es político", sino también "lo personal es científico" y "la ciencia es política". El surgimiento de organizaciones de este tipo ha desafiado el paradigma científico institucional que mantiene que el origen del cáncer de mama es una mezcla de herencia genética y de estilos de vida. Según este paradigma, los factores de riesgo incluyen "antecedentes familiares, sobrepeso, sedentarismo, consumo de alcohol, fumar tabaco, menarquía precoz, menopausia tardía, no haber tenido hijos o no haber dado el pecho" (de Michele, 2017: 24). Sin embargo aproximadamente el 70\% de las mujeres que tienen cáncer de mama no presentan ninguno de esos factores de riesgo. Además, aunque se descubrió que, si se alteran los genes BRCA1 y BRCA2, la probabilidad de desarrollar la enfermedad es muy alta, este tipo de casos sólo supone entre el cinco y el diez por ciento del total (de Michele, 2017). Por otro lado, y como señala esta misma autora, es completamente erróneo separar los estilos de vida del contexto social en

5 Obsérvese la vaguedad del término y su falta de definición. 
que se producen. Por ejemplo, una familia pobre no puede elegir qué comer y se sabe que la pertenencia a grupos vulnerables (clase social o raza) aumenta el riesgo de exposición a sustancias tóxicas relacionadas con el cáncer.

En efecto, se ha comprobado que diversos factores ambientales también son riesgos a tener en cuenta. Los organoclorados, sustancias utilizadas en la elaboración de insecticidas, tienen una larga vida media en el cuerpo humano (hasta 40 años), especialmente en el tejido adiposo, suero y leche. Uno de los principales, el DDT, fue prohibido en 1972 (en España en 1977), pero aún se está utilizando en países africanos como Marruecos y puede volver a entrar en la cadena alimentaria humana a través de comida de origen animal o del agua. También hay evidencia de incremento de riesgo de cáncer de mama por la exposición laboral a radiaciones electromagnéticas y lo mismo pasa con mujeres expuestas a radiaciones ionizantes. Lo mismo sucede con los FTALATOS, una familia de productos químicos "de los que se producen millones de toneladas en todo el mundo y constituyen el principal componente de muchos productos ampliamente usados en le trabajo, en la vida doméstica y en los hospitales" (Valls Llobet, 2017: 19) y con los parabenes, también muy usados como preservantes en comidas, productos cosméticos y preparaciones farmacéuticas (Valls Llobet, 2017).

Las estrategias nacionales para luchar contra el cáncer se centran en la detección, la terapia y el tratamiento médicos, puesto que un enfoque preventivo exigiría cambios socialmente organizados en la forma de vida y los entornos de trabajo de las personas e incluso puede que un modelo completamente nuevo de desarrollo económico y social del que se beneficiarían las personas y las empresas. Eso ha hecho que sistemáticamente se efectúen campañas "supuestamente preventivas" pero que no lo son, sino que son de detección, como aquella sobre el cáncer de mama que utilizaba el eslogan "la detección temprana es la mejor prevención" recomendando el autoexamen regular y la exploración médica. Está claro que un cáncer detectado no se puede prevenir, por lo que se ve claramente que la intención de estas campañas es un modo de cambiar el propósito y definición de intervención sanitaria en este área, pasando de la prevención del cáncer a la prevención de la muerte por cáncer (el eslogan luego pasó a ser "la detección temprana es tu mejor protección". Sin embargo, sigue apareciendo el término "prevención" en las campañas habituales bien de las comunidades autónomas, ayuntamientos, o firmas que se unen a la lucha contra el cáncer. Hay que señalar también que las mamografías, que es el mejor instrumento de exploración del cáncer de mama, no son un instrumento de detección muy sensible.

Los programas de cribado del cáncer de mama siguen en vigor, a pesar de que la proporción riesgo/beneficio es desfavorable, es decir, causan más daño que beneficio. Además de la posibilidad de dar falsos positivos -algo que sucede en casi todas las pruebas médicas- las mamografías pueden detectar cánceres reales pero clínicamente no significativos, con las consecuencias de tratamientos innecesarios con efectos secundarios nocivos y la consiguiente angustia (Forcades i Vila, 2017). Y diversos estudios han mostrado (Forcades i Vila, 2017) que los duros tratamientos de quimioterapia para canceres no-hematológicos sólo han servido en el $90 \%$ de los casos para prologar la vida de los pacientes 3 meses. La causa es que, desde hace 20 años los medicamentos oncológicos aprobados y comercializados no tienen que demostrar que aumentan la supervivencia, sino 
la disminución del volumen del tumor o que no crece. Pero un tumor puede dejar de crecer y eso no significa que el o la paciente esté mejorando o vaya a vivir más tiempo (Forcades i Vila, 2017). Por otro lado, el coste de estos programas de cribado, puede detraer fondos de otras partidas sanitarias.

En primer lugar debe quedar claro de lo anterior que las enormes cantidades de dinero que se meten en la ciencia genética y el gran interés público y la esperanza de promesas del proyecto genoma humano es desproporcionado tanto por lo que se refiere a las intervenciones terapéuticas que el nuevo conocimiento genético probablemente proporcione como con respecto a la eliminación de las posibles mutaciones genéticas que puedan tener los seres humanos. En el primer caso debemos ver más allá de la afirmación extravagante de que un amplio conocimiento del genoma humano va a tener beneficios clínicos evidentes y directos. Como ya señalaba Lewontin en el año 1993, los avances más importantes en la práctica médica del último siglo se han logrado con poca ayuda de la revolución en biología molecular que supuso el descubrimiento de la estructura del ADN. Esos logros "consisten en métodos sumamente mejorados para examinar el estado de nuestro interior, de notables avances en micro aparatos y en modos temáticamente determinados de corregir desequilibrios químicos y matar invasores bacterianos. Nada de esto depende de un conocimiento profundo de los procesos celulares y de ningún descubrimiento de la biología molecular. El cáncer todavía se trata atacando química y físicamente el tejido afectado. Las enfermedades cardiovasculares se tratan mediante cirugía, cuya base anatómica se retrotrae al siglo XIX, y mediante la dieta y tratamientos farmacológicos pragmáticos. Los antibióticos se desarrollaron originariamente sin la más mínima noción de cómo funcionaban. La diabetes sigue tratándose con insulina, igual que hace 60 años, a pesar de toda la investigación sobre la base celular del mal funcionamiento del páncreas" (Lewontin, 1993: 10).

Incluso podríamos ir más allá y considerar, como Lewontin, que la causa última de la mayoría de la mala salud y sufrimiento del mundo no son ni los genes internos ni los patógenos externos, sino las desigualdades estructurales y las formas de carencia de poder que permiten que los patógenos hagan daño. La genética médica, al igual que el desafío biomédico a la enfermedad infecciosa que la precedió, confunde esencialmente el agente o el medio de la enfermedad con su causa y al hacerlo así no ofrece medios creíbles de reemplazar los agentes fijos de la enfermedad por unos nuevos. El genetista "aísla una alteración en el denominado gen del cáncer como la causa del cáncer, mientras que la alteración en el gen puede a su vez haber sido causada por ingesta de algo contaminante, que a su vez fue producido por proceso industrial, que a su vez fue la consecuencia inevitable de invertir dinero al 6\%" (Lewontin, 1993: 46). "El amianto y las fibras de algodón no son las causas del cáncer. Son los agentes de causas sociales, de formaciones sociales que determinan la naturaleza de nuestras vidas como productores y consumidores, y, en última instancia, sólo transformando esas fuerzas sociales podremos llegar a la raíz de los problemas de salud. El desplazamiento de la causalidad de las relaciones sociales hacia agentes inanimados que, así, parecen tener poder y vida propios, es una de las mayores mistificaciones de la ciencia y de sus ideologías" (Lewontin, 1993: 41). Dicho de otro modo, centrarse en esos agentes inanimados, impide ver las auténticas causas - sociales y de desigualdad muchas veces - y las consecuencias, en especial para las mujeres como trabajadoras en, y consumidoras de muchos de esos productos. 


\section{Otro caso de estudio: la maternidad por sustitución}

El desciframiento del genoma humano y la biotecnología, por el momento no cumplen las promesas formuladas: en las prueba genéticas, la farmacogenómica o la terapia génica. Por un lado, los beneficios de las pruebas genéticas serán limitados, por la razón de que la mayoría de las condiciones genéticas son multifactoriales, lo que significa que los resultados de los test genéticos tendrán un valor predictivo muy modesto. Tampoco la fármaco genética o, como se llama ahora, farmacogenómica está dando grandes resultados. La mayoría de los investigadores en farmacología presuponen que los pacientes son un conjunto homogéneo y que, por consiguiente, los medicamentos eficaces y bien tolerados en unos lo serán también en el resto. En otro lugar hemos expuesto los problemas derivados de la no inclusión de mujeres en los ensayos clínicos (García Dauder y Pérez Sedeño, 2017). Pero, además, la experiencia clínica, muestra una realidad compleja: medicamentos que funcionan bien en algunos pacientes son ineficaces o causan reacciones adversas en otros, incluso mortales. Por eso, la farmacogenómica pretende estudiar el efecto de la variabilidad genética de un individuo en su respuesta a determinados fármacos. Visto así, la investigación en este terreno parece muy interesante, pues mediante esta "medicina personalizada", como se la comercializa o publicita, se prometen tratamientos más seguros y eficaces para las enfermedades. Pero las variaciones individuales en la respuesta a los fármacos, puede deberse a la influencia no sólo de factores endógenos, de base genética, sino también a otros factores endógenos como la edad o el sexo del paciente; y, por supuesto a factores exógenos, como la dieta, el uso de agentes xenobióticos como el café, el tabaco, el alcohol, etc.; o factores medioambientales como los ya mencionados.

Y por lo que se refiere a la terapia génica las esperanzas no son mucho mayores. El procedimiento básico consiste en intentar sustituir genes mutados, defectuosos o ausentes por copias de genes sanos. Pero, a pesar de algunos éxitos (como los experimentos de Anderson, en niños "burbuja"), los resultados prometidos no se lograron, y se crearon falsas expectativas debido a una excesiva publicidad y sobrevaloración de los hallazgos. De hecho, la muerte en 1999 de un paciente de 18 años en EEUU, después de recibir un tratamiento innecesario de terapia génica, dañó enormemente la imagen de la terapia génica como se puede ver en algunos titulares que aparecieron en prestigiosa revistas: "La terapia Génica, la pérdida de la inocencia" (Nature Medicine, 2000); "Penosas lecciones" (Molecular Therapy, 2000); "Terapéutico genético, cúrate a ti mismo" (Science, 2000).

Pero hay otros casos que implican la biotecnología que son muy significativos. En otras publicaciones hemos examinado algunas de ellas, como por ejemplo las tecnologías de reconstrucción o de mejora de los cuerpos, como en el caso de los implantes mamarios (Pérez Sedeño, 2012, 2014), o las tecnologías de la reproducción asistida (Pérez Sedeño y Sánchez Torres, 2014). Muchas de las controversias en biotecnología, sobre todo las que tienen que ver con los cuerpos de las mujeres adquieren un tono moral o político. Todo ello nos hace pensar que es mejor no entender la biotecnología como un conjunto de métodos que se pueden desplegar o utilizar con fines y medios diversos, sino como una institución que se ha desarrollado gracias a determinadas visiones ideológicas y políticas (Bliss, 2012). En efecto, las investigaciones que se plantean y las innovaciones que se desarrollan en biotecnología están en gran medida vinculadas a los intereses y prioridades de las agencias de financiación, las empresas o los 
gobiernos. Y, a menudo, los intereses de las mujeres, los ideales democráticos y feministas se quedan a un lado a la hora de obtener financiación. Lo hemos visto en los ejemplos anteriores y queda aún más de manifiesto en los debates sobre la gestación por sustitución ${ }^{6}$.

La gestación por sustitución consiste en implantar un embrión previamente desarrollado por fertilización in vitro (FIV) en una mujer a la que se ha contratado para que lleve a término el embarazo, renunciando a sus derechos de maternidad y entregándose el bebé a quienes han contratado a la mujer. Los actores implicados son muchos, no solamente la madre gestante o el vientre de alquiler, sino también los padres que pueden ser de distinto sexo o del mismo sexo o un solo progenitor, pueden aportar todo el material genético (esperma y óvulos) o sólo parte y que la otra provenga de alguna otra persona no necesariamente de la pareja, e incluso de la propia madre de sustitución. Los casos que se han dado son múltiples en ese sentido. Además intervienen el personal médico, las propias tecnologías y las clínicas donde se llevan a cabo la implantación de los embriones y también el posterior parto.

La creencia subyacente es que la madre de sustitución no aporta ningún "material genético" al feto y, por tanto, carece de cualquier relación con él. El determinismo genético gana una vez más al influjo del medioambiente, a pesar de que el medio en que se desarrolla el feto es el útero de la madre de sustitución, a través del cual se alimenta y crece. Lo paradójico es que es un hecho científico que las informaciones genéticas que hay en el cigoto no son suficientes para que alcance la capacidad de existir con vida autónoma, pues el desarrollo embrionario requiere, obligatoriamente, informaciones operativas exógenas, que, por ahora, solo la madre puede proporcionar en la especie humana.

Pero, además, las TRA, y la maternidad por sustitución como una de ellas, permiten ampliar nuestra noción de parentesco y familia y qué personas pueden tener hijos. Dicho de otro modo, estas tecnologías están cambiando nuestra concepción de la maternidad, de la paternidad, las enfermedades, la naturaleza del ser humano, etc. Y no son sólo un procedimiento para 'atajar' temporalmente la infertilidad, pues son procedimientos para que personas fértiles, pero del mismo sexo o sin pareja, puedan tener descendencia, "por lo que son procedimientos creadores u originadores de maternidades o paternidades" (Pérez Sedeño y Sánchez Torres, 2014: 238).

La gestación por sustitución es una técnica prohibida en España, lo que hace que se convierta en una empresa privada fuera de nuestro país a la cual acuden determinadas personas, por supuesto de determinada clase social, elevada, debido a los altos costes (en Estados Unidos, cuesta entre 100.000 y $150.000 €$, aunque podría ser mayor si surge alguna complicación médica; en Kazajistán, el precio es de unos 80.000 €, en Rusia entre 60.000-70.000 $€$ en Ucrania, unos $50.000 €$ - aunque en estos dos países no se permite para parejas homosexuales - y en Tailandia, entre 35.000 y $40.000 €$ ). Al no estar permitida en España, no hay registros oficiales sobre cuántos niños nacen de esta forma, pero basándose en el número de niños que se registran en los consulados españoles en el extranjero, la Asociación Son Nuestros Hijos (SNH) estima que son unos 1.000 al año ${ }^{7}$. Según la ley española, los contratos

6 Siguiendo a Natalia Fernández (2017), utilizamos esa expresión en lugar de las más populares "maternidad subrogada" o "vientre de alquiler" porque es la que utiliza la Ley 14/2006, de 26 de mayo, sobre Técnicas De Reproducción Humana Asistida.

7 http://www.rtve.es/noticias/20140801/preguntas-respuestas-sobre-gestacion-subrogada-vientres-alquiler/976260. shtml (último acceso, mayo de 2017). 
de gestación por sustitución son nulos de pleno derecho, correspondiendo la filiación a los padres biológicos, pero es posible registrar a esos niños como hijos de los padres que han contratado la maternidad subrogada en determinados casos ${ }^{8}$. Debido a tal prohibición, han proliferado los centros en otros países donde se pueden alquilar mujeres - esto es, una fuerza de trabajo marginalizada y vulnerable económica y tecnológicamente - en las que aplicar estas sofisticadas tecnologías reproductivas, como en India, Ucrania, USA, Rusia o Canadá. Y a pesar de la prohibición, en nuestro país existen empresas que ofrecen esta tecnología y asesoramiento desde el inicio hasta la conclusión, es decir la inscripción de la criatura en el registro (por ejemplo http://officialgestlife.com/, con oficinas en Madrid, Barcelona y los países en los que esta práctica es legal). Así pues, esto se ha convertido en una industria global en el que hay múltiples circuitos de viaje a veces muy complejos.

Los informes y reportajes que aparecen en los medios de comunicación dan cuenta de las complejas narrativas que hay alrededor de esta práctica y los debates que ha suscitado recientemente. Por lo general, estos debates están muy polarizados y se centran en si la globalización del trabajo reproductivo es una explotación de la madre de sustitución o una oportunidad para ella y también si hay que entender estas narrativas como de altruismo de género o como empoderamiento de género. Así pues, se presenta un debate ético entre si esto es un liberalismo reproductivo o una explotación reproductiva (Subramaniam, 2015).

Por un lado, se considera que la gestación por sustitución es una forma tecnológica de reproducción en la que lo más notable es que no media ni el sexo ni la sexualidad. Además, los cuerpos de las mujeres se mercantilizan, al contratar sus úteros. Una de las cosas que hay que tener en cuenta, y que se puede apreciar en los diferentes precios que alcanzan estas técnicas en los distintos países, es que el valor del útero varía dependiendo del país, la clase e incluso el nivel educativo de las mujeres (Sama, 2012). Por ejemplo en la web de la clínica del Centro de Maternidad por Sustitución del Dr. Feskov, ucraniana, pero que ofrece su información en español, aparece un listado de futuras madres sustitutas, en el que, además de una fotografía y datos físicos tales como la edad, altura, peso o grupo sanguíneo, se informa del nivel de estudios o la profesión de la mujer en cuestión ${ }^{9}$.

También hay que tener en cuenta que en las narrativas de las clínicas, la maternidad por sustitución no se presenta como un modelo afectivo de maternidad, sino como un proceso biomédico, en el que la biotecnología toma carta de naturaleza. Así, estas 'madres de alquiler' dan a luz un bebé tras un estricto proceso regulado biomédicamente. Aunque no siempre es así, pues se sabe de la existencia de granjas de mujeres (por ejemplo en India, donde existen actualmente más de 2.000) y en las que viven hacinadas como animales cuya única función es comer y reproducirse ${ }^{10}$.

8 El BOE publicó “Instrucción de 5 de octubre de 2010, de la Dirección General de los Registros y del Notariado, sobre régimen registral de la filiación de los nacidos mediante gestación por sustitución" debido al problema que planteaban los niños nacidos por este procedimiento fuera de España, dado que muchos registros civiles consulares se negaban a inscribirlos debido a que las madres gestantes habían renunciado a su filiación materna en virtud de un contrato de gestación por sustitución.

9 http://www.mother-surrogate.com/the-base-of-surrogate-mothers.php

10 http://www.huffingtonpost.es/yolanda-dominguez/la-nueva-forma-de-someter_b_11830088.html http://blogs. publico.es/puntoyseguido/3743/vientre-de-alquiler-y-mercaderes-de-bebes-en-el-oriente-proximo/ 
En India, por ejemplo, ha surgido toda una narrativa a favor de esta TRA, por considerarla un nuevo nicho de trabajo para las mujeres, que les permite ganar, en nueve meses, lo que sus maridos ganan entre cuatro y diez años. En un reportaje de la CNN en español, de 2013, una mujer, que se identificó como Manjula, de 30 años, y con un hijo y dos hijas, cuenta que ha gestado a un niño por dinero por segunda vez, pues cobraría unos $8.000 \$$ por dar a luz ese niño para una pareja canadiense. Ella y su esposo solían ganar menos de dos dólares al día trabajando en el campo. "La primera vez que vine, construí una casa... Ahora vine por mi hija. Tengo que educarla y casarla. Quiero enseñar las computadoras a mis hijas; tengo que educarlas... lograr que (se) casen con un buen chico" ${ }^{11}$. Como ha señalado Sharmila Rudrappa (citada en Subranamian, 2015), para algunas mujeres este tipo de 'trabajo' es menos explotador que, por ejemplo, trabajar en la industria textil, donde no sólo las jornadas de trabajo son largas y extenuante, sino que, además, en muchas ocasiones sufren violencia y acoso sexual. En cambio, estas 'madres de alquiler' obtienen comida, descanso y cuidados médicos, a los que raras veces pueden acceder.

Pero la maternidad por sustitución también ha recibido muchas críticas. En efecto, se presenta como un modelo desexualizado y medicalizado en el que el cuerpo de la mujer, su útero, se convierte en un bien de consumo, se comercializa. Y la medicalización hace que cambie nuestro concepto de embarazo, pues todo el proceso está sometido a protocolos estrictos que abarcan desde la alimentación, al ejercicio y los periodos de descanso, casi siempre según criterios occidentales aunque las madres por sustitución sean de Tailandia o de India. Y gran parte del dinero, sólo se recibirá si se siguen estos protocolos y se lleva a buen término el embarazo, tal y como se estipula en el contrato.

Por otro lado, y esto es una cuestión que atañe a todas las tecnologías de reproducción asistida, los procedimientos son costosos no sólo económicamente sino también física y psicológicamente. No hay que olvidar que, para implantar un embrión en una mujer, ésta tiene que seguir unos tratamientos hormonales etc. de los que apenas se saben grandes cosas, pues es una técnica que no ha seguido los pasos experimentales que siguen otros tratamientos médicos (Pérez Sedeño y Sánchez Torres, 2014). Psicológicamente también es muy costoso y puede producir ansiedad. Una mujer que ahora trabaja en una plataforma en contra de la legalización de los vientres de alquiler (sic) tuvo dos hijos para una pareja homosexual. Ellos querían un niño y una niña, pero resultó que lo que gestó fueron dos varones. Cuando ella lo supo le produjo mucha angustia el pensar que quizá no querrían quedarse con los dos niños, tuvo preclampsia y estuvo a punto de morir ${ }^{12}$. También hay otras cuestiones implicadas como por ejemplo cuando el bebé resultante tiene algún problema físico o psíquico (como, por ejemplo, síndrome de Down). Ha habido casos en los que la mujer ha querido abortar, pero la firma del contrato previo ha hecho que los "propietarios del vientre de alquiler" no lo permitieran. También casos en los que, con un bebé con problemas, la gestante ha querido seguir adelante con el embarazo, pero los "propietarios," no han querido hacerse cargo del bebé. Esto tiene una doble lectura: por un lado, a la madre gestante se le priva de la maternidad y del amor, mientras que se le concede a otros. Por eso, algunas feministas

11 http://cnnespanol.cnn.com/2013/11/04/vientres-de-alquiler-bebes-hechos-en-india/

12 http://www.noalquilesvientres.com/2017/05/07/una-madre-de-alquiler-no-volvere-a-hacerlo-es-comprar-yvender-un-nino/ 
abogan por la regulación, para así proteger los derechos de las madres por sustitución, que poco o nada tienen que decir en el proceso. Pero el que sea bueno o malo para las mujeres, depende de en qué mujeres pensamos.

Sin embargo, la explotación de mujeres vulnerables no es el único problema que presentan los vientres de alquiler. Incluso si las madres gestantes recibieran un trato exquisito, o si sólo se permitiera esta práctica de forma altruista, persistiría el problema de fondo: la cosificación y explotación tanto de la madre gestante como del niño, que -siguiendo el camino abierto por las técnicas de reproducción asistida- se convierte en un producto de consumo, que se puede encargar cuando se quiera... y devolver cuando la necesidad ya no exista, o no la satisfaga.

\section{4. Últimas reflexiones}

El feminismo no tiene una voz única con respecto al HGP y la maternidad por sustitución, pero hay un eje común: aboga por un análisis profundo sobre la utilización (actual y futura) de los descubrimientos y las invenciones, pues pueden modificar la vida de las mujeres y hacerla más difícil. En especial, el diagnóstico genético prenatal, la medicina fetal, la anticoncepción y las Tecnologías de Reproducción Asistida -últimamente centrando la atención en la maternidad por sustitución- que tienen una relación especial con el HGP, son blanco de críticas por parte del feminismo. En la reproducción humana asistida no están demarcadas claramente las fronteras entre diagnóstico genético prenatal y "control de calidad total". Dicho de otro modo, la medicina preventiva y el control genético que se aplica en la maternidad por sustitución pone de manifiesto un control de calidad del 'producto' a ser concebido (o ya creado). Este control evitará el riesgo de aparición de "defectos de fabricación". La medicina fetal ampliará enormemente su mercado, mediante la medicina preventiva, desarrollada por el Proyecto Genoma Humano, asegurando una clientela específica, el embrión, transformándolo en un "paciente" independiente de quien lo gesta y aboliendo, así, la autonomía de las mujeres para protagonizar la gestación. Son algo secundario para los futuros propietarios del bebé que nacerá.

Al explorar estos casos tan diferentes, a saber la medicina genómica y la maternidad por sustitución, se ve perfectamente cómo los fines, objetivos e imaginarios de la biotecnología contemporánea impactan de manera desigual en las mujeres y en el género. La biotecnología y sus imaginarios parecen reproducir de manera exacta los intereses de poder dentro de la economía política o la bioeconomía, marginalizando a una gran parte de la población, las mujeres.

Para entender la biotecnología debemos contextualizarla, situándola dentro de su contexto político, económico, cultural y nacional, aunque esto último sea problemático, debido al carácter trasnacional y global que ha adquirido. Además, a pesar de las esperanzas liberadoras - de curar enfermedades congénitas, de producir fármacos a la carta o de cumplir los deseos de algunas personas- la biotecnología es cada vez más empresarial, más comercializada y más privada.

Pero esto no debe conducirnos a posturas anti-ciencia o tecnofóbicas, sino a examinar esas prácticas o disciplinas que tienen la capacidad de dañar a los grupos vulnerables o marginalizados, así como las que tienen la capacidad de beneficiar a los grupos poderosos, 
en especial si estos últimos beneficios se extraen de los grupos vulnerables. Por eso es importante la regulación pública de la actividad científica y sus productos, de modo que se puedan utilizar libremente. A la vez, es fundamental garantizar la autonomía de las personas y la soberanía del patrimonio genético de los países, lo que significa ser contrario a la concesión de patentes para la vida, por las implicaciones éticas, sociales, económicas y políticas que ellas conllevan.

Como he señalado en otra parte (Pérez Sedeño, 2017), la ciencia y la tecnología pueden ser poderosos aliados en la lucha por la igualdad de las mujeres y la defensa de sus derechos. Pues pueden mostrar los prejuicios de la sociedad contra las mujeres, por el hecho de serlo, y justificar que se eliminen y se sustituyan por una perspectiva más adecuada. Pero la biotecnología también puede ayudar a perpetuar las inferiores oportunidades de empleo y educativas de las mujeres, así como su posición subordinada en las instituciones de la familia, gubernamentales y otras sociales, a la vez que medicaliza, comercializa e instrumentaliza sus cuerpos. El análisis crítico desde el feminismo podría alertar y ayudar a minimizar los daños.

\section{Referencias}

Bliss, Catherine (2012): Race Decoded: The Genomic Fight for Social Justice, Stanford, CA: Stanford University Press.

Collins, Francis S. et al. (2003): "A vision for the future of genomics research: a blueprint for the genomic era”, Nature, 422 (24 abril): 835-47.

De Michele, Grazia (2017): "Cáncer de mama y medio ambiente: deteniéndolo donde comienza", Mujeres y salud, $\mathrm{n}^{\circ} 42$.

Fernández Jimeno, Natalia (2017): “Nuestros cuerpos, nuestra decisión: Tecnologías reproductivas y participación pública”. Ponencia presentada en el XII International Workshop on Science, Technology and Gender: Knowledge, Practices and Activisms from the Feminist Epistemologies. Madrid, June 21-23.

Forcades, i Vila (2017): “Cáncer y negocio: consideraciones éticas. Mujeres y salud, número 42.

Fox Keller, Evelyn (2002): El siglo del gen, Barcelona: Península.

García Dauder, S. y Pérez Sedeño, Eulalia (2017): Las 'mentiras' científicas sobre las mujeres, Madrid: La Catarata.

International Human Genome Sequencing Consortium (2004): "Finishing the euchromatic sequence of the human genome". Nature 431 (7011): 931-45.

Larrión, Joseán (2011): "Historia de las reuniones de Asilomar. Éxitos y fracasos de la autorregulación en las comunidades tecnocientíficas", Sociología y tecnociencia. Revista digital de sociología del sistema tecnocientífico, $\mathrm{N}^{\circ} 1$, Vol. 1, pp. 63-82. Disponible en https://miaulario.unavarra.es/access/content/user/josean.larrion/Publicaciones/ Historia\%20de \%20las\%20reuniones\%20de\%20Asilomar.\%20\%C3\%89xitos\%20y\%20 fracasos $\% 20 \mathrm{de} \% 201 \mathrm{a} \% 20$ autorregulaci $\% \mathrm{C} 3 \% \mathrm{~B} 3 \mathrm{n} \% 20 \mathrm{en} \% 20 \mathrm{las} \% 20$ comunidades $\% 20$ tecnocient\%C3\%ADficas.pdf. Último acceso, 15 de mayo de 2017.

Lewontin, Richard (1993): Biology as ideology. The Doctrine of DNA, Nueva York: HarperCollins. 
Muñoz Ruiz, Emilio (2001): Biotecnología y sociedad: Encuentros y desencuentros, Madrid: Cambridge University Press.

Pérez Sedeño, Eulalia (2012): “Ciencias y tecnologías del cuerpo: la práctica de la tecnología de los implantes mamarios” en Pérez Sedeño, Eulalia e Ibáñez Martín Rebeca (eds.), Cuerpos y diferencias, Madrid-México: Plaza y Valdés, 131-152.

Pérez Sedeño, Eulalia (2014): "Feminismo, ética y cirugía estética" en Pérez Sedeño, Eulalia y Ortega Arjonilla, Esther (eds.). Cartografías del cuerpo: Biopolítica de la ciencia y la tecnología Madrid: Ed. Cátedra, 91-132.

Pérez Sedeño, Eulalia (2016): "Visiones innovadoras y gobernanza en biomedicina desde la filosofía feminista de la ciencia”. Ponencia presentada en el XI Congreso Iberoamericano de Ciencia, Tecnología y Género, San José de Costa Rica, 26-28 de julio.

Pérez Sedeño, Eulalia (2017): "Filosofía de la ciencia socialmente responsable: ¿Algo nuevo o algo prestado?" Conferencia Inaugural del IV Congreso Iberamericano de Filosofía de la Ciencia y la Tecnología, Salamanca, 3 de julio de 2017.

Pérez Sedeño, Eulalia y Sánchez Torres, Ana (2014): “Asimetrías y olvidos en las tecnologías de reproducción asistida”, en Pérez Sedeño, Eulalia y Ortega Arjonilla, Esther (eds.), Cartografías del cuerpo: Biopolítica de la ciencia y la tecnología. Madrid: Ed. Cátedra, 195-244.

Sama (2012): "Regulation of Surrogacy in Indian Context", Publicado por Sama-Resource Group for Women and Health. Disponible en http://www.samawomenshealth.in/. Último acceso, 24 de junio de 2017.

Subranamian, Banu (2015): “Colonial Legacies, Postcolonial Biologies: Gender and the Promises of Biotechnology", Assian Biotechnology and Development Review, Vol. 17, $\mathrm{n}^{\mathrm{o}} 1,15-36$. 